\title{
Innovative Bogie for Railway Freight Wagon
}

\author{
Marián Moravč́ik ${ }^{1}$, Erik Bašista ${ }^{1, *}$, Miroslav Tomas ${ }^{1}$ \\ 1 Railway Transport Cluster, Štefánikova 887/53, 05801 Poprad
}

\begin{abstract}
In the present article, the authors try to present the most widely used bogies in the world in a popular scientific form compared to the innovative bogie. Listed are the main trends in the development of new bogies with a more detailed description of the requirements that have been achieved in the development of the new bogie bearing the name ZDK-SB. The authors conclude that the conservative approach of railways, in conjunction with legislative requirements, to a certain extent hinders the more vigorous enforcement of new innovative solutions.
\end{abstract}

Keywords: Rail freight bogie; selfsteering; track-friendly; noise.

\section{Introduction}

In the past, the modern railway transportation was characterised in continuous growth of volume of transportation and goods. Today, the situation dramatically changed. It is not only reduction of transported volumes, but also structure of fleets with regard to transportation nature is changing. Majority of transports is performed in unified train sets on the tracks that are used also for passenger transportation. The result is that freight trains have to fit into the time intervals between passenger trains with regard to operating efficiency of the route. But this requirements is not thoroughly only considered in the orders of the freight wagons, in which the brake mode S, i.e. $100 \mathrm{~km} / \mathrm{h}$ operational speed, prevails.

On one hand, the advantages of the freight railway transport for the society are well known, e.g. high area and energetic effectiveness, low green house gas emissions. On the other hand, a market share of the railway transporters of the cargo transportation, as well as its economic efficiency, is low. The way towards larger growth and towards better protection of the environment and resources lead through an innovative freight wagon and bogie.

But any efforts for innovations are limited by the fact that the freight wagon and bogie are dimensioned for 30 year period of service. The second relevant fact is represented by the legislative requirements, which, in comparison with the previous requirements of UIC (the International railway Union - Union Interantionale des Chemins de fer and The International Union of freight wagons), are getting more and more strict due to introduction of the EU legislation. The legislation is based upon TSI - Technical Specifications of Interoperability, Commission Regulations, which are issued as acts. In the past, it was possible, within UIC, to discuss technical issues with the approval bodies during wagon approval. Today in the TSI period, it is not possible to discuss about an act. The requirements are either fulfilled or non-fulfilled. The European standards, to which TSI refer in purely juridical way, are perceived as basis. A wording, quoted in the regulation, is applicable, despite the fact that amendment of the European standard was issued meantime.

Railway undertakings and a private sector operating wagons have considerable capacity and financial expenses related to maintaining their wagon fleet. 
Therefore, a scope of bogie innovation is significantly influenced by a scope of modification of standard bogies (with regard to exchangeability of the standard bogie components) up to several concepts that significantly differ from the existing solutions. Approval of a significantly innovative bogie concept in the railway segment is an extremely expensive issue.

\section{History and Current Situation in Production and Development of Freight Bogies}

In case of freight bogies, we generally speak of a running gear equipment, which is called a running gear in case of two-axle wagons, and a bogie in case of four- and more-axle bogies. Further, we will deal in more details with 2-axle freight bogies.

\subsection{Standard bogies}

The most globally widespread bogie is a bogie denominated three-piece, so called Diamond bogie; in Russia, denominated as Chanin of type denomination 18-100. Regardless of how we call this bogie, the design principle is always the same. The bogie design consists of two longitudinal beams, on which a transverse beam is elastically installed.

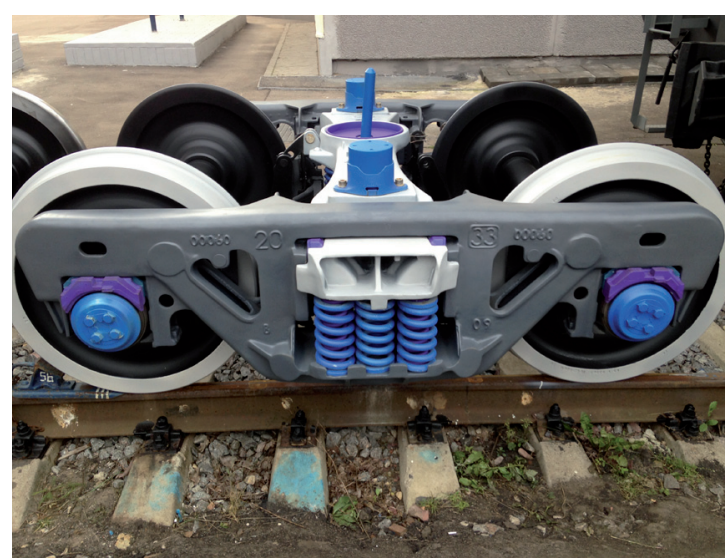

Fig. 1: Three-piece bogie.

For a long time in Europe, a standard for freight wagons was represented by 2-axle wagon equipped with a running gear, from which a bogie of central European type was derived. From 1960s, this bogie is gradually replaced by a boggier of Y25 concept. Development of this bogie headed towards removal of weaknesses of the previous one, towards increase of bearing capacity and operational speed, as well as utility properties related to technology of production, maintenance and reliability of the individual parts. By means of a long-time development, the standard bogies are now in condition when their price is accepted and their weaknesses are tolerated.

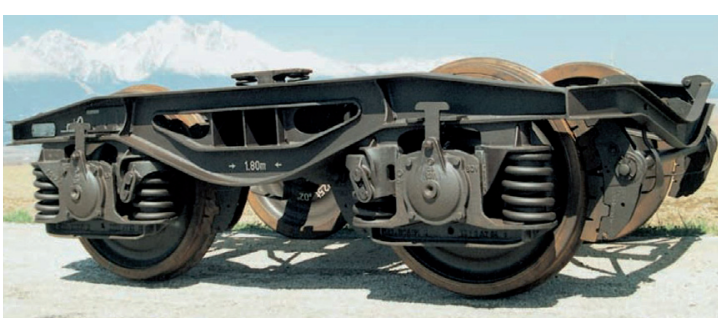

Fig. 2: Standard bogie Y25.

\section{Legal Requirements}

The Currently applicable legislative [2] has introduced two new terms:

\section{- Standardised bogie, \\ - Established bogie:}

$\checkmark$ Bogies of Y 25 family,

$\checkmark$ Bogies of family of 2-axle radially adjustable wheelsets.

A standardised bogie is a bogie with documented fulfilment of requirements of the standard [1] with regard to running and technical characteristics.

A established bogie is a bogie that was approved for operation within UIC in the past, and parameters of which meet the defined parameters of [1].

These new terms are not fully established in the railway terminology yet, because, until now, a standardised bogie was understood to be a conventional Y25 bogie.

Even though the conventional bogie is established, it does not always meets the requirements of new European standards, see [7]. The reason for that are more and more strict limit values defined by the legislative. Knowledge of this fact significantly complicates introduction of the innovative bogies in greater amounts. What is accepted in case of the conventional bogie cannot be accepted in case of a new bogie.

\section{Development Trends in New Bogies}

Requirements in development of new bogies can be summarized as follows:

a) Low tare,

b) Low noise emissions - legislative requirement [4],

c) Reduction of dynamic effects in wheel-rail contact, requirement for so called "Track Friendly",

d) Reduction of wear of wheelsets on curve tracks, 
e) Minimal design speed of $120 \mathrm{~km} / \mathrm{h}$,

f) Securing of running stability in higher speeds,

g) Exchangeability for existing bogies,

h) Improvement of safety against derailment,

i) Preservation of compatibility with the existing track infrastructure,

j) Improvement of braking effect,

k) Reduction of life-cycle costs (LCC).

\section{ZDK-SB Bogie of New Generation}

An effort in development of an innovative ZDK-SB bogie of new generation was to combine the largest possible amount of development trends of freight wagons, and to preserve as much advantages of the conventional bogies as possible. Automatic radial adjustment of wheelsets in combination with optimized suspension characteristic in the vertical direction classify the ZDK-SB bogie into the group of "Track Friendly" bogies. It means that in comparison with the conventional Y25 bogie, the wheelsets get more suitable position against a rail during negotiation of small radius curves, which has a positive effect upon safety and economy of operation.

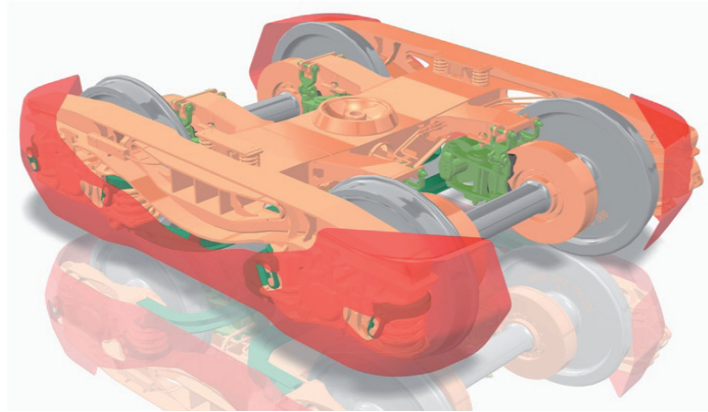

Fig. 3: ZDK-SB bogie.
Tab. 1: Specification of the ZDK-SB bogie.

\begin{tabular}{|l|l|}
\hline Headstock-free frame of the bogie & \\
\hline Maxima, axle load $(\mathrm{t})$ & 22,5 \\
\hline Track gauge $(\mathrm{mm})$ & 1435 \\
\hline Wheel base $(\mathrm{mm})$ & 1800 \\
\hline Wheel diameter Max/Min $(\mathrm{mm})$ & $\varnothing 920 / 840$ \\
\hline Max. speed $(\mathrm{km} / \mathrm{h})$ & 120 \\
\hline Type of brake & Disc brake \\
\hline
\end{tabular}

The ZDK-SB bogie is characterised by two basic principles, see the Fig. 4:

1. Radial adjustability of wheelsets during negotiation of small radius curves.

This property was achieved by using of doublesided damper piston, which provided a clearance in wheelset guiding in longitudinal direction.

2. Connection of wheelsets by means of an U-frame.

After releasing the wheelset guiding in the longitudinal direction, it was necessary to optimize stability of the bogie in higher speeds on the straight track. It was achieved by application of the U-frame, which mutually binds movement between the wheelsets in the longitudinal direction.

By reduction of weight of the bogie, we can achieve a reduction of the overall weight of the wagon. The main meaning for reduction of the bogie, wagon respectively, is that forces necessary for acceleration of sliding and rotational matters of the bogie are smaller. Thus, drawing forces and performances are also smaller, and significant savings of the traction costs are achieved. Reduction of weight directly leads to savings of design materials used for building of

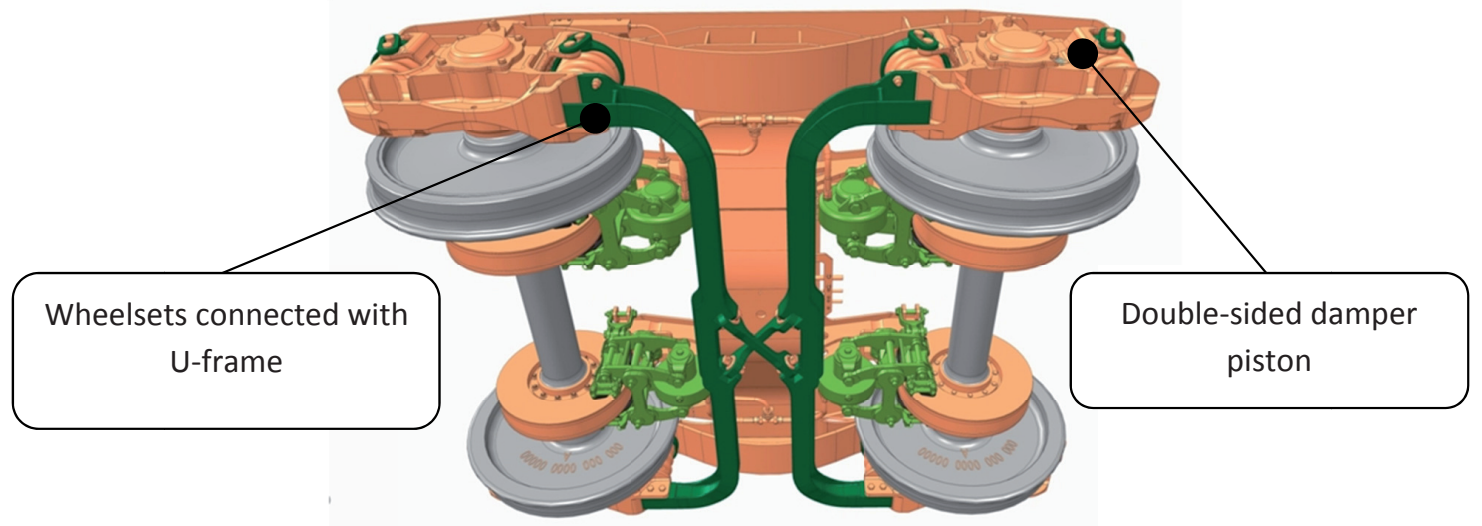

Fig. 4: ZDK-SB - basic principles. 
bogies, and, in some cases, also to reduction of time consumption during production, and thus to reduction of the production costs. Reduction of weight on the unsuspended matters (axle boxes, wheelset, etc.) has a significant effect upon size of the accelerating forces, which adversely load the track superstructure and a vehicle, mainly during higher speed. Significant reduction of the bogie weight was achieved by the headstock-free version of the bogie. The headstock-free frame of the bogie is optimized, with regard to the strength, so that strength requirements, required by the European standard, are met.

Despite great effort in reduction of weight of the innovative bogies, there is not great difference in weight in comparison with the conventional bogies. It is caused by the fact that due to the additional requirements for noise and running characteristics, the bogie frame is loaded with other elements, such as brake components, noise covers, more massive axle box, or a necessity to install the U-frame draw bars. On the contrary, it can be expected that specified requirements, or completely new requirements, will result in slightly increased weight. For the freight wagons, weight is reduced by application of high-strength materials, ratio of the loading weight and the wagon tare is improving, but all this put greater demands upon strength and dynamic dimensioning of new optimized designs of wagons and bogies.

More and more demands are put upon quality of living of inhabitants. One of the factors that affect quality of living and the environment is represented by noise, which negatively influences physical and mental health of inhabitants. Therefore, reduction of noise is one of the main goals of the European Commission. Noise emissions produced by railway transport are a global problem, which significantly affects citizens living around the tracks. Pollution of the environment by surrounding noise is related to noise emitted by road transport, railway and aerial transport, industry, building and other activities.

The road transport is the most dominant source of noise in Europe. It is estimated that approximately 125 million people are affected by road transport noise level Lden greater than $55 \mathrm{~dB}$, including more than 37 million people, who are subjected to noise level Lden of more than $65 \mathrm{~dB}$ [8]. Lden is a common indicator in the EU, which corresponds to the average noise level within the day, evening and night, to which a person is subjected within one year.

After noise caused by road transport, inhabitants are subjected to excessive noise level caused by transportation in the following order:

Railway transport - approximately 8 million people are subjected to noise level Lden of more than $55 \mathrm{~dB}$, Aerial transport - almost 3 million people are subjected to noise level Lden of more than $55 \mathrm{~dB}$,

Industry - 300.000 people are subjected to noise level Lden of more than $55 \mathrm{~dB}$, only in urban areas.

Within development of freight wagons, the manufacturers try to apply some of known solutions, which demonstrably lead to reduction of noise emissions. When speaking about brakes, the disc brake gains ground despite its higher acquisition price and greater weight. It is caused mainly due to higher mileage (lower wheel wear, brake lining wear) and also due to noise reduction. In the ZDK-SB bogie, noise is reduced by means of application of the disc brake, optimized wheel disc (standard pot wheel was replaced with a wheel with straight disc) and by specially developed antinoise covers. A wagon equipped with the ZDK-SB bogies is less noisier than wagon equipped with the conventional Y25 bogies. A radial positioning of wheelsets in small radius curves results in reduction of intensity of slipping between a wheel and rail with a positive effect upon reduction of unpleasant and disturbing sounds.

Within the process of the life cycle costs, all known solutions for noise elimination, on the side of the infrastructure as well as on the side of the wagon, result in enormous increase of these costs. Wagon owners and infrastructure owners are different, and every one of them has its own view of the problem. Today, high demands upon low price and low weight are put in the railway transport. Therefore, the customers are not willing to spend extra costs related to reduction of noise emissions without an additional support. Except for other activities, an effort of the commission for financing is a proposal of bonus system in the form of allowances for operation of silent vehicles; at this place we can mention EU Commission Regulation no.2015/429/EU [6]. It defines the additional bonuses for:

„noiseless wagons" new or existing wagons, which meet the corresponding noise limit values defined in TSI Noise [4]; 
"very quiet wagons and locomotives" are wagons and locomotives with noise emissions that are lower at least by $3 \mathrm{~dB}$ as the corresponding values defined in TSI Noise [4].

By change of characteristic of bogie suspension with an optimized stiffness and damping together with release of wheelset guiding in the longitudinal direction we have achieved reduction of dynamic effects between a wheel and rail. It resulted in lower level of track damage. In comparison with the conventional bogies, the ZDK-SB bogie better adapts to the curve track, which results in reduction of wear of wheel flanges and rails. In comparison with the conventional bogies, size of wheel wear of the ZDK-SB bogie is reduced by $30-40 \%$ (depending upon number of small radius curves on the track).

Safety against derailment is mostly influenced by the vertical loading of a wheel and the horizontal transverse force between a wheel and rail. Derailment occurs when a guiding wheel is relieved for some time, and when, at the same time, the horizontal transverse force is acting upon flange of this wheel. In case of specific nonfavourable proportion of these forces, so called climbing of the flange to the top of rail occurs, and, subsequently, a derailment takes place. Other influences that affect the derailment process are great friction coefficient between wheel and rail, angle of flange inclination and small radius of rail curve, in which large approach angles take place. Thanks to new wheelset guiding with modified suspension characteristic and U-frame, safety against derailment under quasi-static conditions has significantly improved.

\section{Conclusions}

On one hand, there is a strong requirement for introduction of the innovative solutions in the freight wagon bogies; on the other hand, there is a certain caution in adopting non-standard solutions that are not verified in the operation. A potential error will occur with a certain time gap, and it generally brings great financial damage.

The acquisition costs, but mainly the subsequent costs for operation and maintenance of a rolling stock represent the substantial portion of the life Cycle costs. Operation of a rolling stock causes wear and degradation of the tracks. We experience a certain paradox in the railway transport. And it is different in comparison with the road transport used also by us, common motorists, users of roads and highways. Separation of the infrastructure administration from the vehicle operators, within release of business in the railway sector, the following phenomenon occurs. Introduction of the innovative bogie with reduced force effects upon track, which results in reduction of wear in small radius curves, brings the following: On one hand, it means increased costs of the purchaser of the rolling stock in the form of higher price and extra costs in the form of more complicated maintenance (cost savings due to the reduction of the wheelset wear in the form of submitted studies is not accepted. Confirmation in the operation is expected). On the other hand, reduction of track wear occurs due to the effect of wheelset radial adjustability. The infrastructure administrator thus will, after some time, profit from smaller rail wear in the curves. This will apply only when operation of the innovative bogies with reduced force effects upon track will dominate on the specified track sections. Increased costs of one participant will bring a profit for the other participant. Today in Europe, charges for using of a route do not make provision for the improved characteristics of the innovative vehicles, and, therefore, a motivation of the vehicle owners towards the innovations is very small.

\section{Acknowledgments}

The article was elaborated within the research project "Railway freight bogie of new generation" supported by the Agency for support of research and development by the grant no. APVV-14-0595.

\section{References and Notes}

[1] EN 14363 (2005). Railway applications - Testing and Simulations for the acceptance of running characteristics of railway vehicles - Running Behaviour and stationary tests. CEN. Brussels

[2] EN 16235 (2013). Railway applications - Testing for the acceptance of running characteristic of railway vehicles - Freight wagons - Conditions for dispensation of freight wagons with defined characteristics from on-track tests according to EN 14363. CEN. Brussels

[3] Commission Regulation no. 2013/321/EC (2013). on technical specification of interoperability related to the subsystem "rolling stock - freight wagons" of the railway system in the EU, which cancels Decision 2006/861/EC. Official Journal of the European Union. Brussels. 
[4] Commission Regulation no. 1304/2014/EC (2014). on technical specification of interoperability related to the subsystem "rolling stock - noise" that amends the Regulations 2008/232/EC and cancels the Regulation 2011/229/EU. Official Journal of the European Union. Brussels.

[5] Moravčík M, Šimšaj D, Tomas M (2016). Evaluation of results of simulation of ZDK-SB bogie running characteristics according to EN 14363. Tatravagonka. Poprad

[6] Regulatory statute of the Commission no. 2015/429 (2015). which defines methods for implementation of charging of costs related to noise. Official Journal of the European Union. Brussels.

[7] Gerlici J, Moravčík M (2016). Reduction of Dynamic Effects upon Track. Dynamical Problems in Railway Vehicles, volume I, 28-35. Žilina.

[8] EEA Report/No.10/2014 (2014). Noise in Europe. European Enviroment Agency. Denmark

\section{Biographical notes}

Marián Moravčík, Ing., Ph.D.: (born in 1975). Is a Company's chief design engineer in Tatravagonka, Poprad. He graduated at the University of Žilina, Department of mechanics and strength, specialization to Applied mechanics, finished with state exam with diploma work Analyse of parameters of crack propagation in part of welded freight wagon. The Ph.D. - degree he obtained at the University of Pardubice, (zech Republic, Department of rolling stock with the dissertation thesis oriented on the issue of dynamic response of vehicle running in track. His research activities are focused on the freight wagons design and new bogies development.

Erik Bašista, Mgr.: (born in 1982). Is a Company's Director of Project Management Office in Railway Transport Cluster. He graduated at the University of Presov, Faculty of Humanities and Natural Sciences. His research activities are focused on the new innovative technologies in freight wagons and bogies in freight rail business. He works in Tatravagonka Company for last 6 years as a Senior Project Manager. Membership in a "UNIFE Freight Committee", Membership in Virtual Vehicle Austria Consortium "VVAC".

Miroslav Tomas, Ing.: (born in 1980). Is a Chief Executive Officer of Railway Transport Cluster. He graduated at the University of Matej Bell in Banská Bystrica, Faculty of Economics and Management. His research activities are focused on the new innovative technologies in freight wagons and bogies in freight rail business. He works in Tatravagonka Company for last 10 years as a Senior Project Manager. Membership in a "UNIFE Freight Committee", Membership in Virtual Vehicle Austria Consortium "VVAC". Responsible for innovative projects in Railway Transport Cluster. 